\title{
Existence, relatedness and growth needs as mediators between mode choice and travel satisfaction: evidence from Denmark
}

Ingvardson, Jesper Bláfoss; Kaplan, Sigal; de Abreu e Silva, João; di Ciommo, Floridea; Shiftan, Yoram; Nielsen, Otto Anker

\section{Published in:}

Transportation

Link to article, DOI:

$10.1007 / \mathrm{s} 11116-018-9886-3$

Publication date:

2020

Document Version

Peer reviewed version

Link back to DTU Orbit

Citation (APA):

Ingvardson, J. B., Kaplan, S., de Abreu e Silva, J., di Ciommo, F., Shiftan, Y., \& Nielsen, O. A. (2020).

Existence, relatedness and growth needs as mediators between mode choice and travel satisfaction: evidence from Denmark. Transportation, 47, 337-358. https://doi.org/10.1007/s11116-018-9886-3

\section{General rights}

Copyright and moral rights for the publications made accessible in the public portal are retained by the authors and/or other copyright owners and it is a condition of accessing publications that users recognise and abide by the legal requirements associated with these rights.

- Users may download and print one copy of any publication from the public portal for the purpose of private study or research.

- You may not further distribute the material or use it for any profit-making activity or commercial gain

- You may freely distribute the URL identifying the publication in the public portal 


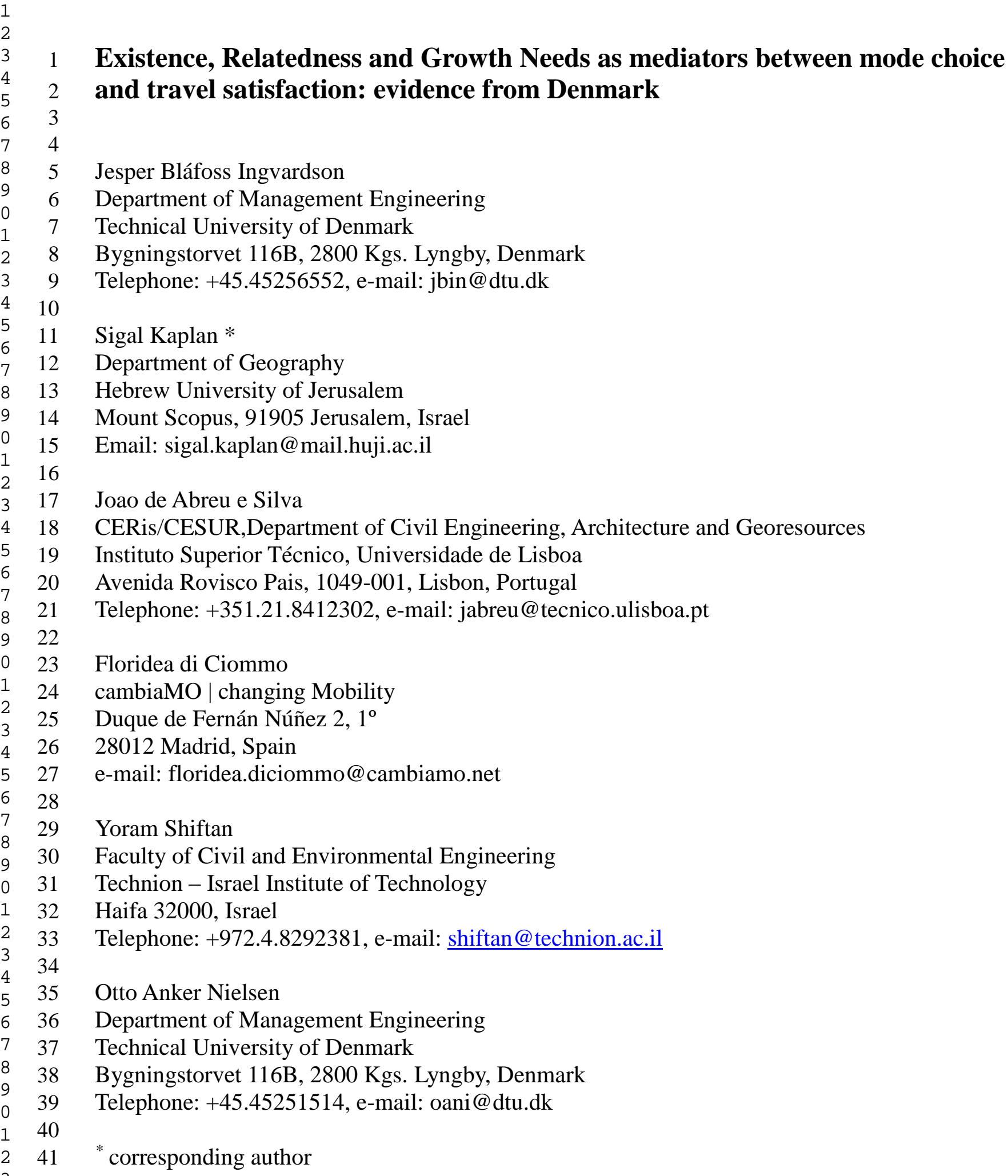
and travel satisfaction: evidence from Denmark

5 Jesper Bláfoss Ingvardson

6 Department of Management Engineering

7 Technical University of Denmark

8 Bygningstorvet 116B, 2800 Kgs. Lyngby, Denmark

9 Telephone: +45.45256552, e-mail: jbin@dtu.dk

10

Sigal Kaplan *

Department of Geography

Hebrew University of Jerusalem

Mount Scopus, 91905 Jerusalem, Israel

Email: sigal.kaplan@mail.huji.ac.il

Joao de Abreu e Silva

CERis/CESUR,Department of Civil Engineering, Architecture and Georesources Instituto Superior Técnico, Universidade de Lisboa Avenida Rovisco Pais, 1049-001, Lisbon, Portugal

Telephone: +351.21.8412302, e-mail: jabreu@tecnico.ulisboa.pt

Floridea di Ciommo

cambiaMO | changing Mobility

Duque de Fernán Núñez 2, $1^{\circ}$

28012 Madrid, Spain

e-mail: floridea.diciommo@cambiamo.net

Yoram Shiftan

Faculty of Civil and Environmental Engineering

Technion - Israel Institute of Technology

Haifa 32000, Israel

Telephone: +972.4.8292381, e-mail: $\underline{\text { shiftan@technion.ac.il }}$

Otto Anker Nielsen

Department of Management Engineering

Technical University of Denmark

Bygningstorvet 116B, 2800 Kgs. Lyngby, Denmark

Telephone: +45.45251514, e-mail: oani@dtu.dk

* corresponding author 
1 ABSTRACT

2 Understanding the link between mode choice and travel satisfaction is essential for promoting 3 sustainable travel by expanding utility theory to include also the eudaimonic value of travel. The

4 study focuses on the hypothesis that more then it's functional value of arriving from A to B, mode 5 choice creates travel experiences that answer high-order needs such as relatedness, autonomy and 6 competence. This study enhances the framework for representing travel mode choice by 7 incorporating the model of human needs as the missing link between mode choice and travel 8 satisfaction. By developing and analysing a large-scale survey from the Greater Copenhagen Area 9 in Denmark, this study empirically proves that commuting mode choice relates to travel

10 satisfaction by answering functional, relatedness and growth needs. The Greater Copenhagen area 11 represents a region where transit, bicycle and car each have large modal shares, hence enabling to 12 validate the approach in a multi-modal environment. Higher bicycle satisfaction relates positively 13 to cycling self-concepts and self-efficacy and negatively to car self-concepts. Greater car use 14 satisfaction increases with car self-concepts and transit use difficulties, and decreases with 15 functional difficulties in car use and better cycling self-efficacy. Higher transit satisfaction mainly 16 relates to experiencing difficulties with other modes. These insights can be used when formulating 17 transport policies and prioritising resources aimed at achieving sustainable mobility patterns. 18 Keywords: Mode choice, travel satisfaction, bicycle, transit, model of needs, ERG 


\section{INTRODUCTION}

Understanding the motivators of habitual travel behaviour is essential to design effective transport policies for promoting and maintaining sustainable travel trends. Travel mode choice is an everyday decision of people whether commuting to work or visiting friends or family. For recurrent trips it is characterised by routine behaviour and based on previous experiences (Carrus et al. 2008). In contrast to making a deliberate mode choice travellers build up travel habits where the choice becomes default based on an expectation of obtaining desired results or goals (Gärling and Axhausen 2003; Aarts et al. 1997). De Vos et al. (2016) suggest that satisfaction plays a cyclical role in travel habit formation and thus affects individual long-term travel behaviour. While short-term trip-based mode choice and travel satisfaction is traditionally explained by utility theory, researchers have noted that there is an additional dimension to the travel experience which is associated with the desire to travel, or "travel-liking" attitudes (Mokhtarian and Salomon, 2001; Ory and Mokhtarian, 2005; De Vos and Witlox, 2016). In a nutshell, besides the utility of getting from the origin to the destination, there is a sense of satisfaction that derives from the travel itself so that, as phrased by Ory and Mokhtarian (2005) to the destination is only half the fun. While travel-liking attitudes can explain in part a higher satisfaction and higher preference for travel, the "new mobilities" paradigm (Jensen 2009; Sheller and Urry 2006), suggests a complementary explanation. According to the "new mobilities" paradigm, more than spatio-temporal movement, travel has a deeper meaning for sense-making, satisfaction, social interaction and identity-production, allowing us to achieve our functional needs along with higher-order emotional needs of independence, self-actualization, self-esteem, and social needs (Jensen 2009). These ideas extend the wider view of the long-identified instrumental, symbolic and affective value of mode choice (e.g. Steg, 2003; 2005) and takes a further step to capture human psychology beyond the already investigated role of lifestyle, attitudes, norms, perceptions, past experience and policy environments (e.g., Van Acker et al. 2010; Salvá et al. 2015; Sigurdardottir et al. 2013). This view also agrees with the research stream suggesting that travel behaviour is governed by a holistic experience comprising perceptions, emotions, past experiences, attitudes, and social climate (Abou-Zeid et al. 2012; Susilo and Cats 2014).

Travel satisfaction has been investigated mainly from the perspective of measuring travel satisfaction as cognitive and affective well-being as proposed by Ettema et al. (2011), associating travel satisfaction to level-of service variables, the characteristics of the built environment, mode related attributes and attitudes and individual socio-economic characteristics (e.g., St-Louis et al. 2014; van Lierop and El-Geneidy 2016; De Vos et al. 2016; Ye and Titheridge 2017). In recent years travel satisfaction has been recognized as related to emotional well-being and life satisfaction (e.g. Abou-Zeid et al. 2012; Friman et al. 2017; Morris and Guerra 2015) and studies have analyzed the direct and indirect effect (through performance of activities at destinations) of travel satisfaction on life satisfaction (Bergstad et al., 2011; De Vos, 2018). Yet, analysing the link between travel mode choice as a decision and travel satisfaction as an experience is still scarce (De Vos et al. 2016; De Vos and Witlox 2017) and understanding the underlying motivators of recurrent travel choices and its conceptualization in the context of well-being remains a challenge (Abou-Zeid et al. 2012).

The current study adds to the literature by suggesting the Theory of Needs as the behavioural paradigm underlying travel satisfaction beyond the functional utility of travel. Moreover, this study empirically shows that mode choice is related to travel satisfaction through satisfying the traveller's physical, emotional and self-esteem needs. Thus, this study verifies and explains the proposition of De Vos et al. (2013) that travel increases well-being through 
satisfaction of physical, relatedness and growth needs, namely by establishing social ties and social bonding, realizing personal goals and increasing the sense of autonomy and competence as drivers of personal growth. . Chiu and Lin (2004) propose to derive a service-quality measure on the basis of the theory of human needs. In accordance, De Vos and Witlox (2017) see travel satisfaction as the missing link driving the formation of travel habits. Singleton (2018) proposes that 'travel eudaimonia' is related to security, autonomy, confidence and health. Shliselberg and Givoni (2018) express similar ideas in contextualising mobility capital by proposing that travel behaviour generates experiences that increase people's social, human, economic and cultural capital, thus generating a sense of autonomy, relatedness and competence which then contribute to a sense well-being. We offer to apply the theory of needs as a rigorous theory allowing to provide a solid behavioural explanation to what drives higher-order travel satisfaction beyond the functional value of travel. Specifically, while the importance of enhancing the instrumental value of travel services in terms of travel time, accessibility, reliability and other level-of-service aspects is uncontested (de Oña et al. 2016), we correlate mode choice and travel satisfaction through the mediator of satisfying human psychological needs, thus proposing Alderfer's (1969) ERG (Existence, Relatedness and Growth) theory as the missing link mediating between mode choice and travel satisfaction. The ERG theory is based on a threefold conceptualisation of human needs: (i) existence (i.e., functional needs), (ii) relatedness (i.e., sense of belonging and togetherness), and (iii) growth (i.e., self-actualization, fulfilment of inner potential and life opportunities). It was developed from Maslow's hierarchical theory of motivation (Maslow 1943), but has the advantage of assuming that each of the three domains can be satisfied independently. According to this view travel mode choice induces a sense of well-being, which is motivated by satisfying the three types of human needs: existence, relatedness, and personal growth needs of self-esteem and self-actualization. Notably, the link between mode choice and psychological needs is already discussed in the literature. Adolescents associate car-use with gaining travel independence and increasing spatial opportunities, self-image through financial status, prestige, and cool feeling, and role as future care-givers (Sigurdardottir et al. 2014). Transit use is correlated with self-esteem and respect for others through perceived spatial equity, price and travel mode fairness (Kaplan et al. 2014), and with 'relational value' through social climate appreciation (Salvá et al. 2015). Cycling enhances multi-dimensional self-esteem comprising of physical, competencies, growth, self-identity and life-values self-concepts (Spotswood et al. 2015). Bicycle lessons are beneficial in increasing cycling competencies, enlarging the activity space, increasing the activity participation and travel independence, and improving the feelings of self-esteem, self-confidence and empowerment (van der Kloof et al. 2014). Last, the transport system is perceived as essential for gaining safety and security in health, employment and social stability, in particular among low-income households, and failing to achieve these needs may result in physical, social, geographical, and economic social exclusion (Lucas 2012). Thus, as suggested by Taniguchi et al. (2014) and Mateo-Babiano (2016) and in accordance with the 'new mobilities' paradigm it is equally important to look at the travel experience from the perspective of meeting a wide spectrum of human needs.

The remainder of the paper presents the proposed framework and mathematical model estimates. Last, we discuss the results and offer policy implications.

\section{METHODOLOGY}

\section{Behavioural framework}


The hypothesised behavioural framework, outlined in Figure 1, relates travel mode choice with travel satisfaction through answering human needs. It is based on a general feedback mechanism between mode choice and satisfaction similar to the framework proposed by De Vos and Witlox (2017) and Shliselberg and Givoni (2018) connecting travel behaviour to experiences that promotes a sense of autonomy, relatedness and competence as a source of eudaimonic well-being. Nevertheless, our framework focuses only on the first part of the feedback loop, which is the link between travel behaviour and satisfaction. Our framework adds the ERG theory of needs as the missing link between travel experience and travel satisfaction including instrumental travel satisfaction and eudaimonic well-being. While both De Vos and Witlox. (2017) and Shliselberg and Givoni (2018) relate travel experiences to well-being outcomes, we offer the underlying behavioural theory that help explaining the proposed connection. Gärling et al. (2002) explain that while the assumption of human needs forms the basis to some motivational theories, others contemplate needs as choice outcomes, as proposed also by Chiu and Lin (2004). Thus satisfaction of needs plays a dual role similarly to the cyclical process in which travel satisfaction derives and drives recurrent choice (De Vos and Witlox 2017). Hence, satisfaction and mode usage do not only depend on traditional attributes of the transport system, but also on how well transport modes are perceived to satisfy higher order needs. When choosing a travel mode, travellers are rewarded in terms of an experienced level of satisfaction. The satisfaction is memorised and to some extent influences future mode choices (Gärling and Axhausen 2003). Gärling et al. (2002) also suggest that the sense of satisfaction is related not only to the positive feedback attained when needs are satisfied but also on negative feedback when difficulties arise as a result from the mode choice. As difficulties are a measure of perceived behavioural control, the perceived difficulties complement the ERG theory by adding functional and psychological barriers affecting the level of satisfaction by impeding self-efficacy expectations (Bandura 1977). In this sense, perceived mode-specific difficulties are a type of mode specific attitudes, thus combining the view Gärling et al. (2002) and De Vos and Witlox (2017) suggesting that travel satisfaction is associated with travel-related attitudes and mode choice and that the latter two are correlated. Finally, feedback deriving from recurrent mode choice strengthens the travel mode commitment and habit, until the goal driven behaviour becomes script-based and the bi-directional relationship between mode choice, satisfaction of needs and travel satisfaction becomes cyclical and entangled (Gärling et al. 2002; Gärling and Axhausen 2003; De Vos and Witlox 2017). The general framework accommodates both single- and multiple-mode commuting routine as travel mode combinations act similarly with respect to difficulties and satisfaction of needs.

The proposed framework in this study encompasses the following research hypotheses:

H1: Satisfying functional and emotional needs of relatedness and growth positively relates to mode use frequency.

H2: Travel satisfaction positively relates to the ability of the travel mode to satisfy individual needs, and negatively correlated with the mode specific difficulties.

H3: bicycle and car use are positively related to togetherness and growth while public transport use is mostly correlated with functional needs.

The first two hypotheses match the ideas expressed by Gärling et al. (2002), De Vos and Witlox (2017) and Schliselberg and Givoni (2018). The third hypothesis stems from the literature regarding the instrumental, symbolic and affective motives for car use (e.g., Steg, 2005) and the added value of the bicycle in generating positive self-concepts (e.g., van der Kloof et al, 2014). 


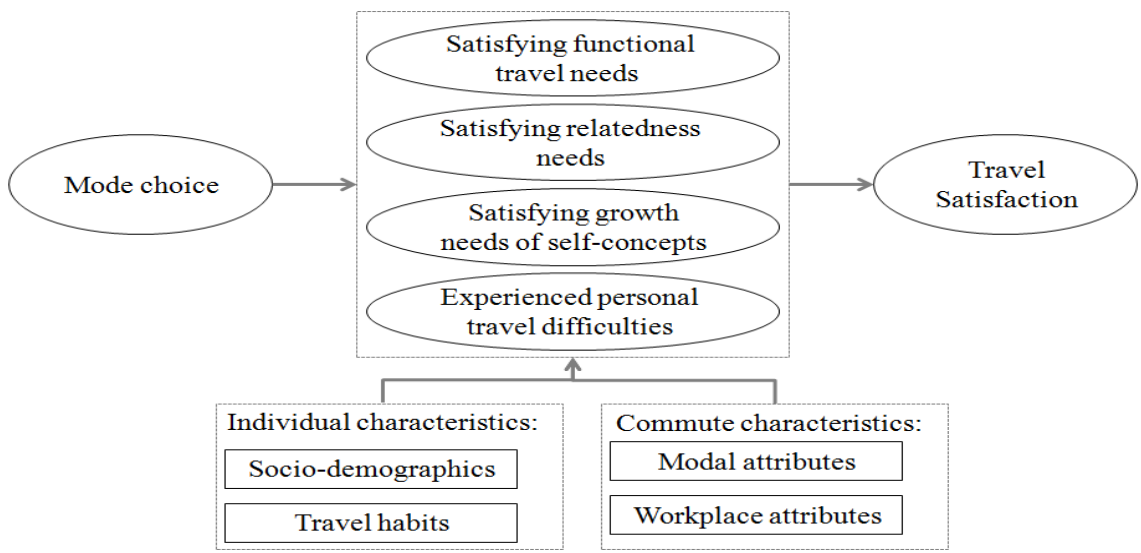

Figure 1: Behavioral framework.

\section{Survey design and administration}

An online survey was tailored in order to investigate our proposed behavioural framework. The survey consisted of four parts: (i) general travel habits and commute characteristics; (ii) ERG dimensions; (iii) mode-specific difficulty statements; (iv) individual and commute characteristics. While previous studies (e.g. De Vos et al., 2016) explored the relation between utility and experience utility in leisure trips, the current study focuses on commuting trips, which constitute $37 \%$ of all trips in the Greater Copenhagen Area, larger than any other trip purpose. The statements were tailored to the commute mode choice context.

Respondents were asked about their travel trends as the frequency of travelling by each mode (i.e., car, bicycle, public transport) and whether they travelled with others in their commute. Walking as a main commuting mode was not elicited because it is rare. According to recent national statistics in Denmark, in 2013 walking comprised only 3\% of the home to work journeys compared to $66 \%$ by car, $20 \%$ by bicycle and $11 \%$ by public transport (Haubold, 2014). Larsen (2010) also reports a share of 3-5\% walking trips for commuting purpose explains it by the travelled distance. According to the Danish travel survey, the average walking distance is 680 meters, while the average commuting distance is 12.3 kilometres and while for trip distances of 500-750 m there are equal shares of people walking, cycling and driving a car, walking trips drop to less than $8 \%$ for trips distance of 2 kilometres (Larsen, 2010). Accordingly, we consider only the most prominent commuting modes of car, bicycle, and public transport. The mode choice frequency was measured on a Likert scale ranging from rarely to daily, with 2-3 times monthly, once weekly, and 2-3 times weekly as intermediate points. Travel habits were elicited independently per mode to allow for multimodality over time (Cherchi and Cirillo 2014; Schlich and Axhausen 2003). Respondents were also asked to rate the level of satisfaction they associate with commuting by each mode on a 5-point Likert scale from very dissatisfied to very satisfied.

The statements measuring the human needs (ERG) dimensions were defined based on a literature review of the most important attributes for travel satisfaction (van Lierop et al., 2018; de Oña and de Oña 2015; Susilo and Cats 2014; De Vos et al. 2016). We hypothesize the ERG constructs to be related to travel satisfaction, in line with Gärling et al. (2002). As a result the phrasing of the ERG constructs was conducted in accordance with the approach of Chiu and Lin (2004) interpreting the ability to satisfy individual needs both from the individual and the service quality perspective. In this respect, some of the statements regarding the satisfaction of needs can also be interpreted as positive attitudes towards a specific mode (e.g., "I feel mentally strengthened when I cycle") while others are expressing travel needs that are not necessarily mode specific (e.g., 
"It is important for me to travel with my colleagues"). The identified attributes were combined with statements on the perceived mode-specific travel difficulties. A total of 50 statements were phrased, namely fifteen on existence needs, ten on togetherness needs, eleven on growth needs, and fourteen on mode-specific travel difficulties. The statements were measured using the 5-point Likert scale ranging from strongly disagree to strongly agree.

Existence need items investigated functional needs when travelling such as health, safety, time and monetary savings, reliability and multi-tasking during travel. They included travel time and costs, avoiding travel hassles such as congestion, parking, and transfers, being able to carry personal belongings, and being able to work or have privacy during the trip.

Relatedness need items investigated the ability to form or enhance interpersonal relationships, feeling part of a group, and conforming to social norms. Interpersonal relationships are formed or enhanced during commuting by spending quality time travelling together with family, friends, and colleagues, and helping others by giving a ride to significant others. In accordance with Danish cycling culture, norms and traditions, feeling part of a group or community was expressed as participating in bike-to-work campaigns or exercising with friends. Conforming to norms was related to individual perceptions regarding the behaviour of people in the social circle of the individual in terms of their commute mode choice.

Growth need items related to developing self-concepts associated with physical ability, competencies (e.g., self-efficacy, overcoming challenges), self-identity related to environmental sustainability and fitness, social self-concept (e.g., social status, prestige), self-actualisation and self-esteem derived from a general optimism, and feeling of life satisfaction.

The perceived difficulties in the commute mode context were expressed as the perceived transit, they are its perceived accessibility, speed, price, crowding and reliability; for cycling, they are weather, hilliness, travel distance and traffic safety; for car use, they are travel expenses, driving stress, perceived difficulties to find parking, traffic safety and traffic congestion.

Individual characteristics included socio-economic information and past travel experiences. The commute characteristics comprise the perceived time and cost associated with the modal choice and situational attributes, namely the home-work distance, parking availability, transit availability at the workplace, and bicycle facilities.

The questionnaire was distributed online to commuters in the Greater Copenhagen Area in June 2016. The questionnaire had identical Danish and English versions and can be provided upon request. Respondents were recruited through 6,000 firms that are all the firms with more than five employees registered in the list of the Danish Bureau of Statistics as located in the region. The selection criterion of at least five employees served to indicate firms that have office location, require commuting and are of sufficient size to participate in the Danish bike-to work campaign. University networks and the social media further distributed the questionnaire, which allowed reaching a large and heterogeneous group of commuters at modest costs.

\section{Mathematical model}

The questionnaire items and the observed individual characteristics led to the formulation of a structural equation model (SEM) to test the hypothesised behavioural framework. SEM allows accommodating measurement errors when the explanatory and the dependent variables are latent multi-dimensional constructs, and modelling simultaneously endogenous latent constructs, their relationship with exogenous observed variables, and their correlation pattern. 
The model contained four sets of equations: measurement equations (eq. 1) linking the measurement indicators (questionnaire items) to the latent ERG and difficulty constructs; structural equations (eq. 2) associating the latent attitudinal constructs with individual socioeconomic characteristics; structural equations (eq. 3) relating the explanatory and the mediator latent constructs; structural equations (eq. 4) linking the latent mediators to the dependent variable.

$$
\begin{array}{lllll}
I_{r n}=Z_{l n}^{*} \alpha_{r}+v_{r n} & \text { and } & v_{n} \sim N\left(0, \Sigma_{v}\right) & \text { for } & r=1, \ldots, R \\
Z_{l n}^{*}=S_{l n} \beta_{l}+\omega_{l n} & \text { and } & \omega_{n} \sim N\left(0, \Sigma_{\omega}\right) & \text { for } & l=1, \ldots, L \\
Z_{l}^{*}=Z_{i} \beta_{i}+\varphi_{l} & \text { and } & \varphi_{l} \sim N\left(0, \Sigma_{\varphi}\right) & \text { for } & l=1, \ldots, L \quad, i=1, \ldots, K \\
Y_{\text {in }}=Z_{l n}^{*} \beta_{z}+\xi_{\text {in }} & \text { and } & \xi_{n} \sim N\left(0, \Sigma_{\xi}\right) & \text { for } & i=1, \ldots, I
\end{array}
$$

11 where $I_{r n}$ is the value of an indicator $r$ of the latent construct $Z^{*}{ }_{l n}$ as perceived by respondent $n, Z^{*}{ }_{l n}$ 12 is the value of latent construct $l$ for respondent $n, S_{l n}$ is a vector of $M$ respondents' observed 13 individual characteristics, and $Y_{\text {in }}$ is a vector of travel users' satisfaction levels. Error terms are 14 expressed as elements $\omega_{l n}, v_{r n}, \xi_{i n}$ of the vectors following a normal distribution with respective 15 covariance matrix $\Sigma_{\omega}, \Sigma_{v}, \Sigma_{\xi}$, while parameters to be estimated are $\alpha_{r}, \beta_{l}, \beta_{i}$, and $\beta_{z}$. Considering $\mathrm{R}$ 16 indicators translates into writing $\mathrm{R}$ measurement equations and estimating an $(R \times 1)$ vector $\alpha$ of 17 parameters (i.e., one parameter is estimated for each equation), while considering $L$ latent 18 constructs translates into writing $L$ structural equations and estimating an $(M \times L)$ matrix of $\beta$ 19 parameters (i.e., $M$ parameters are estimated for each equation).

The vector $\alpha$ of parameters of the measurement equations and the vector $\beta$ 's of parameters of the structural equations were estimated using Mean- and Variance-adjusted Weighted Least Squares (WLSMV) (Muthén and Muthén, 2017). The goodness-of-fit was measured using the relative CFI (comparable Fit Index) and the absolute Root Mean Square of Approximation (RMSEA).

\section{RESULTS}

\section{Sample characteristics}

The survey yielded 1,481 complete responses (92.7\% of the survey entries), which is an adequate sample size for the chosen statistical approach of a structural equation model considering the often used rule of thumb of minimum criterion of 1000 observations, or ten responses per indicator (Nunnally et al. 1967). Table 1 describes the sample socio-economic characteristics in comparison with the values found in the Danish national travel survey from the Greater Copenhagen Region, which are shown in brackets for comparison.

Table 1: Sample characteristics, compared with the Danish national travel survey.

\begin{tabular}{llllll}
\hline Variable & \multicolumn{4}{l}{ Categories (values from the national survey are presented in brackets) } & \\
\hline Gender & Male & Female & & & \\
& $44.6(46.7)$ & $55.4(53.3)$ & & & \\
\hline Age & $18-30$ & $30-45$ & $46-65$ & 65 & \\
& $13.0(30.7)$ & $37.2(26.0)$ & $47.2(41.4)$ & $2.6(2.0)$ & \\
\hline Car accessibility & Yes & No & & & \\
& $68.4(78.4)$ & $31.6(21.6)$ & & & \\
\hline Family status & Single no & Couple no & Single with & Couple with & Other \\
& children & children & children & children & \\
& $14.3(15.9)$ & $31.3(29.9)$ & $4.7(3.7)$ & $44.0(34.5)$ & $5.7(16.0)$ \\
\hline
\end{tabular}




\begin{tabular}{llllll}
\hline Employment status & Full time & Part time & Other & & \\
& $87.6(74.0)$ & $7.6(26.0)$ & 4.9 & & \\
\hline Monthly income & $0-3000$ & $3000-4500$ & $4500-6000$ & $6000-7500$ & $>7500$ \\
$(\$)$ & $6.0(32.8)$ & $15.6(15.7)$ & $35.0(14.5)$ & $23.0(12.0)$ & $20.3(25.1)$ \\
\hline Education level & High-School & Tertiary & Bachelor & Graduate & \\
& $7.2(11.7)$ & $23.3(38.3)$ & $22.4(29.6)$ & $47.2(20.4)$ & \\
\hline Commute origin & Copenhagen & Suburbs & Rural & & \\
& $40.0(36.8)$ & $34.5(32.6)$ & $25.5(30.6)$ & & \\
\hline Commute destination & Copenhagen & Suburbs & Rural & & \\
& $51.3(43.4)$ & $44.5(32.1)$ & $4.2(24.5)$ & & \\
\hline Commute distance & $0-5 \mathrm{~km}$ & $5-10 \mathrm{~km}$ & $10-20 \mathrm{~km}$ & $20-30 \mathrm{~km}$ & $>30 \mathrm{~km}$ \\
& $17.3(13.5)$ & $21.4(16.2)$ & $25.5(17.4)$ & $13.8(17.8)$ & $22.1(35.1)$ \\
\hline
\end{tabular}

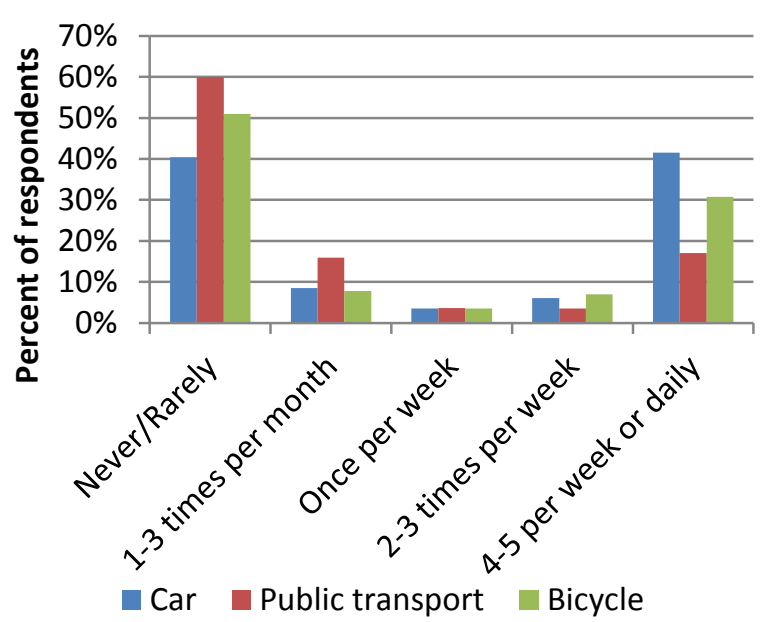
according to the Danish National Travel Survey.

The sample characteristics are reasonably in line with the survey aim and scope to target commuters in the Greater Copenhagen Area. The sample is gender balanced and includes adults in the working age, most of the respondents are full-time employees and either reside or work in the study area. The commuting destination indicates the existence of both radial and local commuting patterns, in line with the mono-centric metropolitan structure. The car ownership is in line with the one in the region according to the Danish Bureau of Statistics, and the same applies to the distribution of commuting distance with an average commute of $20 \mathrm{~km}$, and $38.7 \%$ of the sample commuting up to $10 \mathrm{~km}$ each way. The sample corresponds to the Danish national travel survey apart from education, income and workplace location, which is reasonable considering that the employees were recruited through companies rather than directly.

Figure 2 illustrates the travel frequency and satisfaction with each of the three modes and shows their correspondence. The level of satisfaction is generally high and similar for the car and the bicycle as commute modes, compared to transit for which only less than $40 \%$ are satisfied or very satisfied. The modal shares of car, bicycle and transit at least 4-5 times a week or daily are respectively $42 \%, 31 \%$ and $17 \%$, in line with the modal shares of $45 \%, 32 \%$ and $18 \%$ in the region

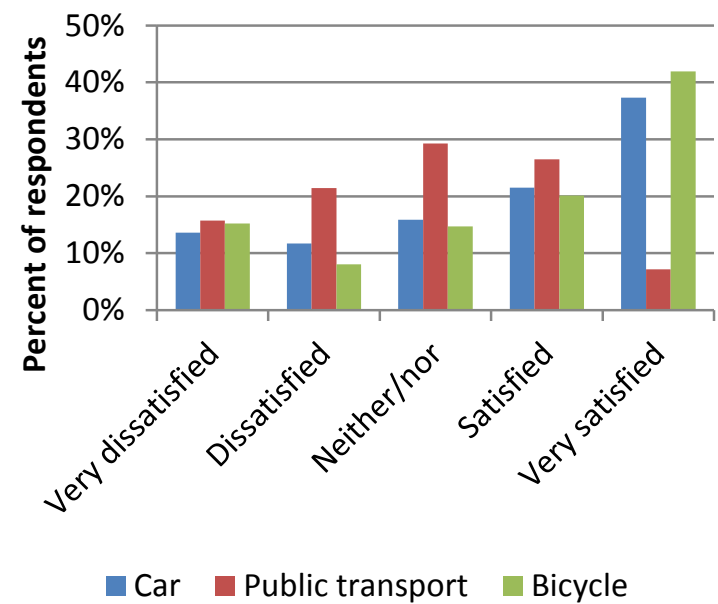

Figure 2: Frequency of use (left) and level of satisfaction (right) with car, transit and bicycle for the commute trip. 
Factor analysis

Exploratory factor analysis (EFA) was used to obtain insights about the underlying constructs of existence, relatedness and growth needs and the travel difficulties. This was chosen due to the flexibility of EFA as compared to confirmatory factor analysis (CFA) as it was possible to analyse the structure between survey items where some were mode-specific, e.g. items related to growth needs and travel difficulties, and some were a combination of mode-specific and generic, e.g. items related to existence needs and relatedness needs. The EFA effectively reduced the number of factors for the subsequent SEM.

The survey data showed good internal consistency with Cronbach's alpha $=0.792$, and statements with no single items having a measure of sampling adequacy of less than 0.70 . The determinant of the Spearman correlations matrix equal to 7.4E-12 established the existence of correlations without multi-collinearity, and the Bartlett's test for sphericity rejected the null hypothesis of an identity correlations matrix. Principal axis factoring with orthogonal Varimax rotation generated the seven factors in table 2 where the dominant items were defined as those with an absolute value greater than 0.30 (Kline 1994). The internal consistency for each factor was good as the Cronbach's alpha's were all above 0.70 (Miller 1995).

Factors F1, F2, F4, and F5 are about satisfaction of personal needs, while in F3, F6 and F7 the phrasing is more about person's difficulties associated with the mode. Factor F1 "positive cycling self-concepts" is associated with the ability of commuting by bicycle to satisfy growth needs of self-efficacy, self-actualization, optimism and self-esteem. Factor F2 "travel togetherness" incorporates all survey statements related to relatedness needs, including joint travel, shared travel experiences, helping others and participating in joint activities related to the social milieu and work environment. Factor F3 "functional difficulties associated with car use" includes statements related to the preference for avoiding difficulties associated with car use and are related to negative driving experience such as difficulties to find parking, congestion, driving stress, etc. Factor F4 "positive car self-concepts" incorporates statements associated with the ability of commuting by car to satisfy growth needs of self-efficacy, travel independence and social status. Factor F5 "satisfying functional needs" relates to personal functional needs such as arriving safely on time, saving time and being able to travel when needed without worrying about transfers. Factor F6 "cycling self-efficacy" gathers statements related to the person's coping with challenges while cycling, i.e. reversed travel difficulties, such as the weather conditions, hilly terrain, distance and traffic. Factor F7 "functional difficulties in transit" includes the personal experience or perception of transit being slow, expensive, crowded and unreliable.

Table 2: $\quad$ Rotated factor matrix loadings.

\begin{tabular}{llr}
\hline Factor name & Item & $\begin{array}{c}\text { Factor } \\
\text { loading }\end{array}$ \\
\hline & It is important for me to get exercise & 0.528 \\
& It is important for me to get fresh air & 0.512 \\
F1 & I feel mentally strengthened when I cycle & 0.878 \\
Positive cycling & I feel on top and with good energy when I cycle & 0.894 \\
self-concepts (0.916) & I enjoy challenging myself physically when I cycle & 0.736 \\
& I feel good about myself when I cycle & 0.853 \\
& I feel good about contributing to the environment when I cycle & 0.657 \\
\hline F2 & It is important for me to travel with my colleagues & 0.776 \\
Travel togetherness & It is important for me to spend quality time together with others on the way & 0.753 \\
$(0.890)$ & It is important for me to bring/collect others on the way & 0.483
\end{tabular}


It is important for me to exercise by bicycle with friends

It is important for me to talk about a shared hobby related to travel mode

It is important for me to participate in Bike-to-Work campaigns

0.857

It is important for me to be part of a bicycle culture

It is important for me to save money

It is important for me to avoid driving stress

It is important for me to avoid road congestion

It is important for me to avoid worrying about parking

F3

Car use functional

difficulties $(0.818)$

I believe it is important not to contribute to congestion

0.684

0.774

0.397

0.473

0.465

0.509

Transit is inaccessible to me

0.362

Driving a car is too expensive for me

$-0.332$

Searching for parking takes too long for me

0.523

Driving a car is too stressful for me

0.643

0.763

Driving a car is too dangerous for me

0.602

Driving a car is too unreliable (congestion) for me

0.657

I live life to the fullest when I drive my car (e.g. By listening to music) 0.673

F4

Driving a car is a cool way to travel

0.829

Driving a car makes me feel optimistic and high-on-life

0.877

Positive car self-concepts (0.905)

Driving a car makes me feel that I get the most out of every situation

0.758

I feel more independent when I drive a car 0.610

It is important for me to arrive safely

0.531

It is important for me to carry my things

0.568

F5 It is important for me to save time

0.496

It is important for me to go wherever and whenever I want

0.477

Satisfying functional needs (0.746)

It is important for me to have privacy during my transport

0.309

It is important for me to avoid congestion in transit

0.506

It is important for me to avoid having to change transport mode / line $\quad 0.565$ It is important for me to arrive on time

0.574

F6

Biking is difficult for me because of the weather $(\mathrm{R})$

0.548

Biking is difficult for me because of the terrain $(R)$

0.681

Cycling self-efficacy (0.756)

Biking is difficult for me because of the distance $(\mathrm{R})$

0.688

Biking is dangerous for me due to other traffic $(\mathrm{R})$

0.448

Transit is too slow for me

F7

Transit is too expensive for me

0.575

Functional difficulties in transit (0.756)

1 Note: (R) - Reversed coding in the case of negatively-phrased items; Cronbach's alpha in parenthesis.

2 Model estimation results

3 The model was estimated using the standard WLSMV estimator in MPlus, due to the violation of 4 normally distributed data for all items according to the Shapiro-Wilk test, and because it provides the best option when modelling ordered data such as 5-point Likert data (Brown 2006). The tested model revealed goodness-of-fit measures in terms of RMSEA equal to 0.050 , which is consistent with the recommended values (Hu and Bentler 1999). The CFI equal to 0.903 is far above the recommended minimum values for empirical data (Browne and Cudeck 1992).

Tables 3 and 4 show the parameters estimates, the standard errors and critical ratios (C.R.) - ratio of parameter estimate, showing the significance of each parameter. Table 3 presents the structural equations linking the latent ERG constructs and the perceived difficulties to socio-economic characteristics, and table 4 shows the structural equations relating the travel satisfaction to the ERG constructs and the perceived experience travel difficulties. Figure 3 shows the path diagram of the model structure with solid lines denoting positive relation, dashed lines denoting negative relation. Figure 3 shows only the significant effects at a 0.05 significance level. 
Table 3: Estimates of the structural equations linking the ERG constructs to the socio-economic characteristics.

\begin{tabular}{|c|c|c|c|}
\hline Factor name & & est. & C.R. \\
\hline \multirow{4}{*}{ Positive cycling self-concepts (F1) } & Male & -0.107 & -2.43 \\
\hline & Car availability & 0.156 & 2.84 \\
\hline & Home location: Copenhagen suburbs & 0.104 & 2.13 \\
\hline & Bicycle travel time greater than $30 \mathrm{~min}$ & 0.260 & 5.32 \\
\hline \multirow{6}{*}{ Travel togetherness (F2) } & Age 45-65 & -0.180 & -1.88 \\
\hline & Education: vocational & -0.326 & -2.58 \\
\hline & Education: Tertiary & -0.374 & -2.70 \\
\hline & Education: Bachelor & -0.357 & -3.03 \\
\hline & Education: Graduate & -0.548 & -4.96 \\
\hline & Workplace location: Copenhagen city & -0.314 & -3.21 \\
\hline \multirow{2}{*}{ Car use functional difficulties (F3) } & Male & -0.070 & -1.55 \\
\hline & Car availability & -0.124 & -2.33 \\
\hline \multirow{7}{*}{ Positive car self-concepts (F4) } & Age $30-45$ & -0.298 & -3.69 \\
\hline & Age 45-65 & -0.346 & -4.23 \\
\hline & Car availability & 0.121 & 2.01 \\
\hline & Education: Bachelor & -0.211 & -2.00 \\
\hline & Education: Tertiary & -0.399 & -4.09 \\
\hline & Student & -0.288 & -1.87 \\
\hline & Workplace location: Copenhagen suburbs & -0.206 & -2.55 \\
\hline \multirow{2}{*}{ Satisfying functional needs (F5) } & Male & -0.224 & -4.10 \\
\hline & Age $45-65$ & -0.191 & -2.25 \\
\hline \multirow{6}{*}{ Cycling self-efficacy (F6) } & Male & 0.200 & 4.55 \\
\hline & Income: high & 0.159 & 3.01 \\
\hline & Travelling with children & 0.124 & 1.52 \\
\hline & Monthly travel costs less than 500 DKK & 0.342 & 3.16 \\
\hline & Travel time: less than $10 \mathrm{~min}$ & 0.459 & 4.59 \\
\hline & Travel time: $10-50 \mathrm{~min}$ & 0.374 & 6.49 \\
\hline \multirow{3}{*}{ Functional difficulties in transit (F7) } & Age $30-45$ & -0.427 & -4.45 \\
\hline & Age $45-65$ & -0.436 & -4.48 \\
\hline & Age higher than 65 & -0.834 & -4.21 \\
\hline
\end{tabular}


Table 4: Estimates of the structural equations relating the travel satisfaction with the latent ERG constructs and travel mode use

\begin{tabular}{|c|c|c|c|c|c|}
\hline \multirow[b]{2}{*}{$\begin{array}{l}\text { Dependent (mediator) } \\
\text { variables }\end{array}$} & \multirow[b]{2}{*}{ Explanatory variable } & \multicolumn{2}{|c|}{ Direct effect } & \multicolumn{2}{|c|}{ Total effect } \\
\hline & & est. & C.R. & est. & C.R. \\
\hline \multirow{3}{*}{$\begin{array}{l}\text { Positive cycling } \\
\text { self-concepts (F1) }\end{array}$} & Perceived transit use frequency & -0.098 & -3.58 & -0.129 & -4.27 \\
\hline & Perceived bicycle use frequency & 0.214 & 6.36 & 0.396 & 12.89 \\
\hline & Perceived car use frequency & - & - & -0.262 & -10.85 \\
\hline Travel togetherness (F2) & Perceived bicycle use frequency & 0.105 & 2.31 & 0.105 & 2.31 \\
\hline \multirow{3}{*}{$\begin{array}{l}\text { Car use functional } \\
\text { difficulties (F3) }\end{array}$} & Perceived transit use frequency & 0.097 & 3.23 & 0.097 & 3.23 \\
\hline & Perceived bicycle use frequency & 0.129 & 3.65 & 0.129 & 3.65 \\
\hline & Perceived car use frequency & -0.492 & -13.19 & -0.492 & -13.19 \\
\hline \multirow{2}{*}{$\begin{array}{l}\text { Positive car self-concepts } \\
\text { (F4) }\end{array}$} & Perceived bicycle use frequency & -0.127 & -3.32 & -0.127 & -3.32 \\
\hline & Perceived car use frequency & 0.367 & 8.59 & 0.367 & 8.59 \\
\hline \multirow{3}{*}{$\begin{array}{l}\text { Satisfying functional needs } \\
\text { (F5) }\end{array}$} & Perceived transit use frequency & -0.068 & -1.86 & -0.097 & -2.66 \\
\hline & Perceived car use frequency & 0.123 & 2.43 & 0.346 & 8.01 \\
\hline & Perceived bicycle use frequency & - & - & -0.033 & -3.12 \\
\hline \multirow{3}{*}{ Cycling self-efficacy (F6) } & Perceived transit use frequency & -0.189 & -7.02 & -0.189 & -7.02 \\
\hline & Perceived bicycle use frequency & 0.350 & 10.97 & 0.350 & 10.97 \\
\hline & Perceived car use frequency & -0.292 & -7.57 & -0.292 & -7.57 \\
\hline \multirow{2}{*}{$\begin{array}{l}\text { Functional difficulties in } \\
\text { transit (F7) }\end{array}$} & Perceived transit use frequency & -0.075 & -2.00 & -0.075 & -2.00 \\
\hline & Perceived car use frequency & 0.323 & 6.99 & 0.323 & 6.99 \\
\hline \multirow{7}{*}{ Car satisfaction } & Car use functional difficulties (F3) & -0.311 & -10.37 & -0.311 & -10.37 \\
\hline & Positive car self-concepts (F4) & 0.232 & 8.89 & 0.232 & 8.89 \\
\hline & Cycling self-efficacy (F6) & -0.065 & -1.79 & -0.065 & -1.79 \\
\hline & Functional difficulties in transit (F7) & 0.139 & 5.08 & 0.139 & 5.08 \\
\hline & Perceived bicycle use frequency & - & - & -0.092 & -4.65 \\
\hline & Perceived transit use frequency & - & - & -0.028 & -2.00 \\
\hline & Perceived car use frequency & - & - & 0.302 & 10.36 \\
\hline \multirow{7}{*}{ Transit satisfaction } & Car use functional difficulties (F3) & 0.127 & 3.58 & 0.127 & 3.58 \\
\hline & Satisfying functional needs (F5) & -0.052 & -1.53 & -0.052 & -1.53 \\
\hline & Cycling self-efficacy (F6) & 0.063 & 1.70 & 0.063 & 1.70 \\
\hline & Functional difficulties in transit (F7) & -0.274 & -6.68 & -0.295 & -7.92 \\
\hline & Perceived bicycle use frequency & - & - & 0.040 & 2.76 \\
\hline & Perceived transit use frequency & - & - & 0.026 & 1.78 \\
\hline & Perceived car use frequency & - & - & -0.187 & -6.39 \\
\hline \multirow{6}{*}{ Bicycle satisfaction } & Positive cycling self-concepts (F1) & 0.366 & 12.38 & 0.366 & 12.38 \\
\hline & Positive car self-concepts (F4) & -0.101 & -3.72 & -0.101 & -3.72 \\
\hline & Cycling self-efficacy (F6) & 0.232 & 6.90 & 0.354 & 11.45 \\
\hline & Perceived bicycle use frequency & - & - & 0.239 & 11.17 \\
\hline & Perceived transit use frequency & - & - & -0.091 & -5.98 \\
\hline & Perceived car use frequency & - & - & -0.201 & -9.36 \\
\hline \multirow{3}{*}{ Correlation patterns } & Car satisfaction - transit satisfaction & 0.107 & 3.94 & - & - \\
\hline & Car satisfaction - bicycle satisfaction & 0.117 & 4.11 & - & - \\
\hline & $\begin{array}{l}\text { Transit satisfaction - bicycle } \\
\text { satisfaction }\end{array}$ & 0.125 & 4.40 & - & \\
\hline
\end{tabular}


2 Figure 3: Model structure relating the mode use to satisfaction via the ERG constructs

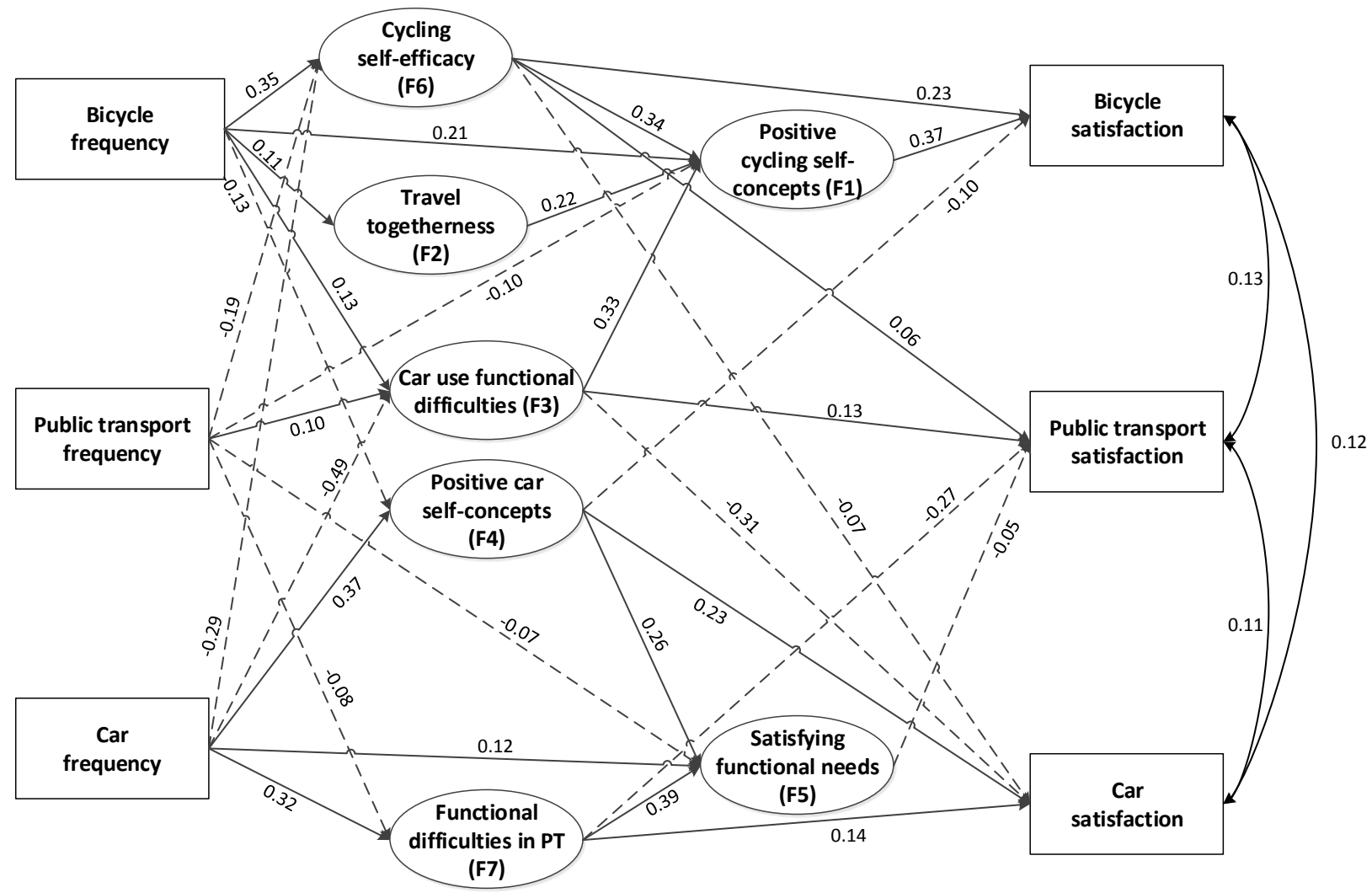

\section{DISCUSSION}

The relation between mode choice, ERG needs, experienced difficulties and travel satisfaction

The model structure confirmed hypothesis H1 that experienced mode choice is positively and significantly related to the perceived existence, relatedness and growth needs, as well as negatively correlated to the perceived difficulties. The model structure confirms hypothesis $\mathrm{H} 2$ that travel satisfaction is related not only to functional needs, but also to relatedness and growth needs. Furthermore, needs satisfaction varies across modes, which is mostly evident when comparing positive self-concepts for bicycle (F1) and car (F4). Despite being similar concepts of higher-order needs the model results suggest that travel self-efficacy leads to the development of positive self-concepts for bicyclists whereas this is not the case for car and public transport users. Moreover, the model confirms $\mathrm{H} 3$ that bicycle and car use are positively related to togetherness and growth while public transport use is mostly correlated with functional issues.

The level of satisfaction with the commute mode is generally high and similar for the car and the bicycle as commute modes, compared to transit in line with previous studies (De Vos et al., 2016; Morris and Guerra, 2015; St-Louis et al., 2014; Ye and Titheridge, 2017). The specific results show that higher bicycle satisfaction is linked positively to cycling self-concepts and self-efficacy, and negatively to car self-concepts. Higher cycling frequency and lower car and transit use frequency are associated with increased perception of cycling self-efficacy and travel togetherness. The two factors have equal role as mediators between cycling frequency and cycling self-concepts, namely higher cycling frequency leads to better feelings of self-efficacy and togetherness motivating a better feeling of self-actualization and self-esteem, which in turn leads to higher satisfaction. This hierarchy agrees with Maslow's pyramid of needs where growth needs 
are higher-order than relatedness and functional needs. Nevertheless, in agreement with the ERG model, the relatedness needs are satisfied in parallel to the functional needs and the two are almost equally important in developing cycling self-concepts. Functional difficulties associated with car use also link positively to cycling self-concepts, establishing the car and bicycles as the main competitors in the Danish transport arena.

Greater car satisfaction associates positively with car self-concepts and transit use difficulties, and negatively with functional difficulties in car use and cycling self-efficacy. Positive car self-concepts are related positively to car use and negatively to cycling frequency. The functional difficulties in car use are associated with higher transit and cycling frequency and lower car use, while perceived difficulties in transit use are associated with higher car use and lower transit use. However, the strongest influence to car satisfaction is the functional difficulties of the car itself, which also influences public transport satisfaction positively, and positive cycling concepts leading to higher bicycle satisfaction.

Greater transit satisfaction correlates positively with greater difficulties in car use and negatively with difficulties in transit use and the ability to satisfy travel needs by car. The importance of these factors shows that the car, rather than the bicycle, is the main competitor of transit, and that the use of transit derives by existence or functional needs. Greater transit satisfaction links to lower perceived cycling self-efficacy, meaning that transit satisfaction is greater for people who feel less comfortable in using the bicycle or the car.

The correlation patterns across the satisfaction from the three modes show positive correlations, meaning that higher satisfaction from a certain mode translates into higher general satisfaction also from the other modes. Namely, people whose needs are satisfied feel satisfied with the transport system in general, and dissatisfaction from one mode translates into a system-wide dissatisfaction.

\section{The relationship between the ERG needs, experienced difficulties and respondents' characteristics}

Cycling self-concepts are stronger for women, while cycling self-efficacy is stronger for men, indicating gender differences in satisfying growth needs. For women, cycling satisfies mainly self-identity of being sportive and environmentally sustainable, optimism, and self-esteem, while for men cycling satisfies physical challenges, namely self-efficacy and developing competencies. Cycling self-concepts are stronger for people cycling half an hour or more in their commuting trip, suggesting reciprocity between the development of cycling self-concepts and the cycling amount. Cycling self-efficacy is stronger for people travelling with children (albeit not statistically significant), possibly due to the need to serve as role models, and people with local travel patterns, as indicated by the low travel costs and time.

Positive car self-concepts increase with car availability and young age. Namely, young

Travel togetherness is more important at younger ages, for people working in city centre people and people with higher levels of car availability develop stronger car self-concepts. Functional difficulties are perceived as stronger by women and people with lower car availability levels, indicating again a reciprocity effect, namely people who see functional difficulties in driving have lesser tendency to own a car and vice versa. Functional travel needs such as multi-tasking, safety, and privacy, are associated positively with women and are perceived as more important at both younger and third age, indicating a shift in the travel preferences with life-cycle stages. locations, and seems to diminish with education length. This points to the possibility of needs 
being determined by lifestyles. Young travellers prefer to travel together with friends and young families with their children.

The perceptions regarding the functional difficulties related to transit diminish with age, with young people showing the greatest dislike for transit.

We found a positive correlation (small but significant) between satisfaction by different modes, so people who are more satisfied with travel are more satisfied with all modes and the ones that are less satisfied are less satisfied with all modes. This finding suggests that there is a higher dimension of satisfaction common to all modes similar to findings from the studies of De Vos et al. (2016), St-Louis et al. (2014) and Ye and Titheridge (2017) who found that a preference for a certain mode can (positively or negatively) affect travel satisfaction when using other modes. The ERG theorem, empirically validated in the current study, provides an interesting explanation to these results. When ERG needs are satisfied, travellers develop a positive stance towards travel in general, thus increasing their satisfaction also with other travel modes compared to people whose ERG are not met during travel.

\section{Limitations and further research themes}

While the current study provides important insights, the data source used in this study is not without limitations. First, this study uses cross-sectional data, which is less efficient than panel data to investigate the assumptions of the relationship between need satisfaction and travel use because it cannot capture trip-level modal shifts. Further research could investigate the consistency of results across other travel purposes and population groups. Second, our data does not include joint trips because commuting trips are mostly individual trips. Nevertheless, for leisure travel joint travel needs to be considered. Third, it seems like, there is an attitudinal shift, where the younger generation shows more negative attitudes towards public transport. There are studies addressing the impact of life events such as child birth, income change or retirement on mobility biographies (e.g., Lanzendorf, 2010) and studies focusing on changing travel trends towards multi-modality and more sustainable modes among younger generations (e.g., Kuhnimhof et al., 2012; DelBosc and Currie, 2013). However, there is little knowledge regarding attitudinal changes towards travel modes among younger generations, which remains a theme for further research. Last, a challenge of comparing different travel satisfaction from different travel modes is that the difference on how individual value and change/adjust their satisfaction may differ overtime and perhaps differ between en-route and ex-post the trip. The questionnaire in this study applies to the overall satisfaction of commuters with their commuting choices overall rather than per trip. In this study, we asked commuters to contemplate on their satisfaction from their modal choice rather than to rank their satisfaction on a trip-by-trip basis. The distinction between 'trip satisfaction' and 'satisfaction with daily travel' is important because of the major difference between the two concepts (e.g., De Vos and Witlox, 2017). The questionnaire also elicited the weekly frequency of taking each mode so the satisfaction is evaluated for commuting trends rather than on a trip-by-trip basis. The proposed approach is reasonable because satisfying relatedness and growth needs take time but further research could address the trip-based need satisfaction for comparison.

\section{CONCLUSIONS}

This study provides empirical evidence that the interdependence of mode use and travel satisfaction is related to the ability of the travel mode experience to satisfy functional and emotional human needs of relatedness and growth. Similarly to De Vos et al. (2016) who investigated leisure trips, we show that also for commuting trips, travel encompasses subjective 
well-being. Specifically, while the traditional utility-based approach considers only the attributes of the transport mode, the results show that, social and self-esteem needs increase travel satisfaction for commuting trips. Thus, the results confirm the hypothesis that positive travel experience and attitudes towards travel modes are related not only to level-of-service parameters, but also to their ability to satisfy emotional needs by triggering feelings of togetherness, self-efficacy and positive self-concepts. In addition, while traditional research focuses on travel disutility embedded in the attributes of the transport, this study shows that negative emotions and evaluation relate to individual difficulties, thus personalizing also the disutility. The results empirically confirm previous studies suggesting similar relations (e.g., De Vos and Witlox, 2017; Schliselberg and Givoni, 2018).

Policy wise, the findings show that increased sense of self-efficacy, togetherness, and positive self-concepts are strong motivators of satisfaction. Hence, encouraging their development in relation to sustainable modes and relevant branding may result in successful long-term shift towards sustainable travel. The results show that, at least in Denmark, the main competitor of the car is the bicycle as commute travel mode, not only because both are private modes, but also because both are related to the formation of positive self-concepts that lead to higher self-esteem. This advantage of the bicycle is an important consideration in the decision to integrate bicycle and transit use and in promoting bicycle infrastructure. Because according to De Vos and Witlox (2017) habit formation is based on a cyclical process driven by recurrent travel satisfaction, emphasis should be on long-term policies and promotion of sustainable travel from an early age. An important question for discussion is the transferability of the Danish results to other countries. The ERG theory of needs stems from the area of psychology and while the prioritization of needs may vary across population and circumstances, the general theory holds universally. The motivator for conducting the study in Denmark is the ability to examine satisfaction of needs and difficulties in a multi-modal environment due to high accessibility and use for all transport modes. In a multi-modal environment, people experience different modes and are thus able to evaluate the suitability of the various modes to their functional and emotional needs based on their travel experiences. Because satisfaction of needs is a choice outcome, these results would be difficult or nearly impossible to obtain in car-oriented or transit-oriented travel environments where people become captives of one mode or have a limited modal accessibility and choice. Nevertheless, results from more recent studies in Poland and on Polish immigrants in Denmark show that cycling answers existence, growth and relatedness needs also for Poland (Kaplan et al., 2018a,b), which encourages the transferability of our results also to other countries. Hence, while the transferability of the results to other countries merits further exploration, Denmark can serve as a benchmark for understanding the functional and emotional effects of each mode and their relation to travel satisfaction when choice is fully available.

\section{ACKNOWLEDGEMENTS}

The study is supported by the $\mathrm{PhD}$ dissertation scholarship financed by the Danish Metro Company, the IPTOP research project (Integrated Public Transport Optimisation and Planning) funded by Innovation Fund Denmark, and EU Cost action 1209 for Transport Equity Analysis. The authors wish to thank three anonymous reviewers for their contribution to improve earlier versions of this manuscript.

\section{AUTHORS' CONTRIBUTION}

All authors contributed jointly to this study. The idea for the study, the application of the ERG theory was initiated by Sigal Kaplan and developed in collaboration with Yoram Shiftan. Floridea 
di Ciommo hosted Jesper Ingvardson for a short term scientific mission (STSM) in which he developed the survey under joint supervision with Sigal Kaplan. The data analysis was conducted by Jesper Ingvardson under the supervision of Sigal Kaplan and João de Abreu e Silva, who hosted Jesper Ingvardson for an STSM and advised on the paper writing and revision process. The data collection was facilitated and the Danish aspects of the study were advised by Otto Anker Nielsen. The paper writing was conducted by Sigal Kaplan and Jesper Ingvardson and assisted by comments from the other co-authors.

\section{CONFLICTS OF INTEREST STATEMENT}

9 On behalf of all authors, the corresponding author states that there is no conflict of interest.

10

11

12

13

14 15

16

17

18

19

20

21

22

23

24

25

26

27

28

29

30

31

32

33

\section{REFERENCES}

Abou-Zeid, M., Witter, R., Bierlaire, M., Kaufmann, V., Ben-Akiva, M.: Happiness and travel mode switching: Findings from a Swiss public transportation experiment. Transp. Policy. 19, 93-104 (2012). doi:10.1016/j.tranpol.2011.09.009

Alderfer, C.P.: An empirical test of a new theory of human needs. Organ. Behav. Hum. Perform. 4, 142-175 (1969). doi:10.1016/0030-5073(69)90004-X

Bandura, A.: Self-efficacy: Toward a unifying theory of behavioral change. Psychol. Rev. 84, 191-215 (1977). doi:10.1037/0033-295X.84.2.191

Bergstad, C.J., Gamble, A., Gärling, T., Hagman, O., Polk, M., Ettema, D., Friman, M., Olsson, L.E.: Subjective well-being related to satisfaction with daily travel. Transportation 38 (1), 1-15 (2011). DOI 10.1007/s11116-010-9283-z

Brown, T.: Confirmatory Factor Analysis for Applied Research. The Guilford Press, New York (2006)

Browne, M.W., Cudeck, R.: Alternative Ways of Assessing Model Fit. Sociol. Methods Res. 21, 230-258 (1992)

Carrus, G., Passafaro, P., Bonnes, M.: Emotions, habits and rational choices in ecological behaviours: The case of recycling and use of public transportation. J. Environ. Psychol. 28, 51-62 (2008). doi:10.1016/j.jenvp.2007.09.003

Chen, C.F., Chao, W.H.: Habitual or reasoned? Using the theory of planned behavior, technology acceptance model, and habit to examine switching intentions toward public transit. Transp. Res. Part F Traffic Psychol. Behav. 14, 128-137 (2011). doi:10.1016/j.trf.2010.11.006

Cherchi, E., Cirillo, C.: Understanding variability, habit and the effect of long period activity plan in modal choices: a day to day, week to week analysis on panel data. Transportation (Amst). 41, 1245-1262 (2014). doi:10.1007/s11116-014-9549-y

34 Chiu, H., Lin, N.: A service quality measurement derived from the theory of needs. Serv. Ind. J. 24, 35 187-204 (2004). doi:10.1080/02642060412331301202

36 de Oña, J., de Oña, R.: Quality of Service in Public Transport Based on Customer Satisfaction 
Surveys: A Review and Assessment of Methodological Approaches. Transp. Sci. 49, 605-622

2 (2015). doi:10.1287/trsc.2014.0544

de Oña, J., de Oña, R., Eboli, L., Mazzulla, G.: Index numbers for monitoring transit service quality. Transp. Res. Part A Policy Pract. 84, 18-30 (2016). doi:10.1016/j.tra.2015.05.018

De Vos, J.: Analysing the effect of trip satisfaction on satisfaction with the leisure activity at the destination of the trip, in relationship with life satisfaction. Transportation (2018) DOI $10.1007 / \mathrm{s} 11116-017-9812-0$

De Vos J., Schwanen, T., Van Acker, V., Witlox, F.: How satisfying is the Scale for Travel Satisfaction? Transportation Research Part F 29 (2015) 121-130.

De Vos, J., Mokhtarian, P.L., Schwanen, T., Van Acker, V., Witlox, F.: Travel mode choice and travel satisfaction: bridging the gap between decision utility and experienced utility. Transportation (Amst). 43, 771-796 (2016). doi:10.1007/s11116-015-9619-9

De Vos, J., Schwanen, T., Van Acker, V., Witlox, F.: Travel and Subjective Well-Being: A Focus on Findings, Methods and Future Research Needs. Transp. Rev. 33, 421-442 (2013). doi:10.1080/01441647.2013.815665

De Vos, J., Witlox, F.: Do people live in urban neighbourhoods because they do not like to travel? Analysing an alternative residential self-selection hypothesis. Travel Behaviour and Society 4, 29-39 (2016). doi:10.1016/j.tbs.2015.12.002

De Vos, J., Witlox, F.: Travel satisfaction revisited. On the pivotal role of travel satisfaction in conceptualising a travel behaviour process. Transp. Res. Part A Policy Pract. 106, 364-373 (2017). doi:10.1016/j.tra.2017.10.009

Delbosc, A., Currie, G.: Causes of Youth Licensing Decline: A Synthesis of Evidence, Transport Reviews, 33:3, 271-290, (2013). doi: 10.1080/01441647.2013.801929

Ettema, D., Gärling, T., Eriksson, L., Friman, M., Olsson, L.E., Fujii, S.: Satisfaction with travel and subjective well-being: Development and test of a measurement tool. Transp. Res. Part F Traffic Psychol. Behav. 14, 167-175 (2011). doi:10.1016/j.trf.2010.11.002

Friman, M., Gärling, T., Ettema, D., Olsson, L.E.: How does travel affect emotional well-being and life satisfaction? Transp. Res. Part A Policy Pract. 106, 170-180 (2017). doi:10.1016/j.tra.2017.09.024

Gärling, T., Eek, D., Loukopoulos, P., Fujii, S., Johansson-Stenman, O., Kitamura, R., Pendyala, R., Vilhelmson, B.: A conceptual analysis of the impact of travel demand management on private car use. Transp. Policy. 9, 59-70 (2002). doi:10.1016/S0967-070X(01)00035-X

33 Gärling, T., Axhausen, K.W.: Introduction: Habitual travel choice. Transportation (Amst). 30, 34 1-11 (2003). doi:10.1023/A:1021230223001

35 Haubold, H.: Commuting: who pays the bill? Overview of fiscal regimes for commuting in Europe 36 
Available

online

at:

2 https://ecf.com/sites/ecf.com/files/141117-Commuting-Who-Pays-The-Bill_2.pdf

3

4

5

6

7

8

9

10

11

12

13

14

15

16

17

18

19

20

Hu, L., Bentler, P.M.: Cutoff criteria for fit indexes in covariance structure analysis: Conventional criteria versus new alternatives. Struct. Equ. Model. A Multidiscip. J. 6, 1-55 (1999). doi:10.1080/10705519909540118

Jensen, O.B.: Flows of Meaning, Cultures of Movements - Urban Mobility as Meaningful Everyday Life Practice. Mobilities. 4, 139-158 (2009). doi:10.1080/17450100802658002

Kaplan, S., de Abreu e Silva, J., Di Ciommo, F.: The relationship between young people's transit use and their perceptions of equity concepts in transit service provision. Transp. Policy. 36, 79-87 (2014). doi:10.1016/j.tranpol.2014.08.004

Kaplan, S., Wrzesinska, D., Prato C.: Role of Culture and Needs in Cycling Habits of Female Immigrants from a Driving-Oriented to a Cycling-Oriented Country. Paper number 18-02033, accepted for publication at the Transport Research Review (2018a).

Kaplan, S., Wrzesinska, D., Prato C.: The Role of Existence, Relatedness, and Growth Needs in the Intention to Use Conventional and Electric Bike sharing in a Driving-Oriented Country. Proceedings of the TRB annual meeting 2018b. Paper number 18-02044.

Kuhnimhof, T., Armoogum, J., Buehler, R., Dargay, J., Denstadli, J.M., Yamamoto T.: Men Shape a Downward Trend in Car Use among Young Adults-Evidence from Six Industrialized Countries. Transport Reviews, Vol. 32, No. 6, 761-779, (2012). DOI: 10.1080/01441647.2012.736426

Kline, P.: An easy guide to factor analysis. Routledge, London, UK (1994)

Lanzendorf, M.: Key Events and Their Effect on Mobility Biographies: The Case of Childbirth, International Journal of Sustainable Transportation, 4:5, 272-292, (2010) DOI:10.1080/15568310903145188

Larsen, M.K.: Analysis of the Danish Travel Survey data on private and public transportation. Annual Transport Conference at Aalborg University (2010) ISSN 1603-9696, Available online at: http://www.trafikdage.dk/papers_2010/406_MarieKLarsen.pdf

27 Lucas, K.: Transport and social exclusion: Where are we now? Transp. Policy. 20, 105-113 (2012). 28 doi:10.1016/j.tranpol.2012.01.013

29 Maslow, A.H.: A theory of human motivation. Psychol. Rev. 50, 370-396 (1943). 30 doi: $10.1037 / \mathrm{h} 0054346$

31 Mateo-Babiano, I.: Pedestrian's needs matters: Examining Manila's walking environment. Transp. 32 Policy. 45, 107-115 (2016). doi:10.1016/j.tranpol.2015.09.008

33 McFadden, D.: Economic Choices. Am. Econ. Rev. 91, 351-378 (2001)

34 Miller, M.B.: Coefficient Alpha: A Basic Introduction from the Perspectives of Classical Test 35 Theory and Structural Equation Modeling. Struct. Equ. Model. 2, 255-273 (1995) 
1 Mokhtarian, P.L., Salomon, I., 2001. How derived is the demand for travel? Some conceptual and 2 measurement considerations. Transportation Research Part A 35 (8), 695-719. doi: 3 10.1016/S0965-8564(00)00013-6

4 Morris, E.A., Guerra, E.: Mood and mode: does how we travel affect how we feel? Transportation 5 42, 25-43 (2015). doi:10.1007/s11116-014-9521-X

Muthén, L.K., Muthén, B.O.: Mplus User's Guide. Muthén \& Muthén, Los Angeles, CA (2017)

Nunnally, J.C., Bernstein, I.C., ten Berge, J.M.: Psychometric theory. McGraw-Hill, New York (1967)

9 Ory, D.T., Mokhtarian, P.L., 2005. When is getting there half the fun? Modeling the liking for 10 travel. Transportation Research Part A 39 (2-3), 97-123. doi: 10.1016/j.tra.2004.09.006

11 Salvá, J.R., Sierra, M., Alanis, A.K.J., Kaplan, S., Prato, C.G.: Role of Social Climate in Habitual 12 Transit Use by Young Adults to Work and Leisure Activities. Transp. Res. Rec. J. Transp. Res. 13 Board. 2512, 22-30 (2015). doi:10.3141/2512-03

14 Schlich, R., Axhausen, K.W.: Habitual travel behaviour: Evidence from a six-week travel diary. 15 Transportation (Amst). 30, 13-36 (2003). doi:10.1023/A:1021230507071

16 Shliselberg, R., Givoni, M. Motility as a policy objective, Transport Reviews, 38:3, 279-297 17 (2018), DOI: 10.1080/01441647.2017.1355855

18 Sheller, M., Urry, J.: The New Mobilities Paradigm. Environ. Plan. A. 38, 207-226 (2006). 19 doi:10.1068/a37268

Sigurdardottir, S.B., Kaplan, S., Møller, M.: The motivation underlying adolescents' intended time-frame for driving licensure and car ownership: A socio-ecological approach. Transp. Policy. 36, 19-25 (2014). doi:10.1016/j.tranpol.2014.07.001

Sigurdardottir, S.B., Kaplan, S., Møller, M., Teasdale, T.W.: Understanding adolescents' 24 intentions to commute by car or bicycle as adults. Transp. Res. Part D Transp. Environ. 24, 1-9 25 (2013). doi:10.1016/j.trd.2013.04.008

26 Singleton, P.A., 2018. Walking (and cycling) to well-being: modal and other determinants of 27 subjective well-being during the commute. Travel Behaviour and Society, In Press. 28 doi:10.1016/j.tbs.2018.02.005

29 Spears, S., Houston, D., Boarnet, M.G.: Illuminating the unseen in transit use: A framework for 30 examining the effect of attitudes and perceptions on travel behavior. Transp. Res. Part A Policy 31 Pract. 58, 40-53 (2013). doi:10.1016/j.tra.2013.10.011

32 Spotswood, F., Chatterton, T., Tapp, A., Williams, D.: Analysing cycling as a social practice: An 33 empirical grounding for behaviour change. Transp. Res. Part F Traffic Psychol. Behav. 29, 22-33 34 (2015). doi:10.1016/j.trf.2014.12.001

35 St-Louis, E., Manaugh, K., van Lierop, D., El-Geneidy, A.: The happy commuter: A comparison of 
1 commuter satisfaction across modes. Transp. Res. Part F Traffic Psychol. Behav. 26, 160-170

2 (2014). doi:10.1016/j.trf.2014.07.004

3 Steg, L.: Can public transport compete with the private car? IATSS Res. 27, 27-35 (2003). 4 doi:10.1016/S0386-1112(14)60141-2

5 Steg, L.: Car use: Lust and must. Instrumental, symbolic and affective motives for car use. Transp. 6 Res. Part A Policy Pract. 39, 147-162 (2005). doi:10.1016/j.tra.2004.07.001

7 Susilo, Y.O., Cats, O.: Exploring key determinants of travel satisfaction for multi-modal trips by 8 different traveler groups. Transp. Res. Part A Policy Pract. 67, 366-380 (2014).

9 doi:10.1016/j.tra.2014.08.002

10 Taniguchi, A., Grääs, C., Friman, M.: Satisfaction with travel, goal achievement, and voluntary 11 behavioral change. Transp. Res. Part F Traffic Psychol. Behav. 26, 10-17 (2014). 12 doi:10.1016/j.trf.2014.06.004

13 Van Acker, V., Van Wee, B., Witlox, F.: When Transport Geography Meets Social Psychology: 14 Toward a Conceptual Model of Travel Behaviour. Transp. Rev. 30, 219-240 (2010). 15 doi:10.1080/01441640902943453

16 van der Kloof, A., Bastiaanssen, J., Martens, K.: Bicycle lessons, activity participation and 17 empowerment. Case Stud. Transp. Policy. 2, 89-95 (2014). doi:10.1016/j.cstp.2014.06.006

18 van Lierop, D., Badami, M.G., El-geneidy, A.M.: What influences satisfaction and loyalty in public 19 transport? A review of the literature, Transport Reviews, 38:1, 52-72, (2018) DOI: $10.1080 / 01441647.2017 .1298683$

van Lierop D., El-Geneidy A.: Enjoying loyalty: the relationship between service quality, customer satisfaction, and behavioral intentions in public transit. Res Transp Econ 59:50-59 (2016) doi:10.1016/j.retrec.2016.04.001

Ye, R., Titheridge, H.: Satisfaction with the commute: The role of travel mode choice, built environment and attitudes. Transp. Res. Part D Transp. Environ. 52, 535-547 (2017). doi:10.1016/j.trd.2016.06.011

\section{AUTHORS' BIO}

\section{Jesper Bláfoss Ingvardson}

Jesper Bláfoss Ingvardson is currently a Post.Doc. at the Department of Management Engineering at the Technical University of Denmark. He has a $\mathrm{PhD}$ from 2018 in public transport planning with focus on travelers' behavior and preferences, specifically with an emphasis on analyzing differences in satisfaction and effects of various public transport modes. Prior to his $\mathrm{PhD}$ he was a research assistant working on multiple projects related to public transport planning.

\section{Sigal Kaplan *}

Sigal Kaplan is Associate Professor at the Hebrew University of Jerusalem and an external Collaborator at the Universidad politecnica di Madrid (TRANSyT at UPM), formerly Associate 
Professor at the Technical University of Denmark (DTU) and Eleonore Trefftz visiting professor at the Technical University of Dresden (TU-Dresden). She teaches and conducts research in the area of behavioural geography, focusing on sociological and psychological processes that motivate sustainable choices in transport and urban planning. Sigal has published 58 papers in scientific journals and she is the vice-chair of the Israeli Geography Association.

\section{Joao de Abreu e Silva}

João de Abreu e Silva is an Associate Professor at Instituto Superior Técnico- Universidade de Lisboa, Portugal and a researcher at CESUR/CEris. His research interests are mainly focused on travel behavior and its interactions with land use patterns. He is a member of three TRB standing committees and vice-chair of the board of the World Society for Transport and Land Use Research (WSTLUR) and member of the International Steering Committee for the Travel Survey Conference (ISCTSC).

\section{Floridea di Ciommo}

Dr. Floridea Di Ciommo is co-founder of the cooperative cambiaMO| changing MObility. She used to be responsible for research on sustainable mobility and travel behaviour at the UPC16 Barcelona Tech and at the UPM, Madrid. She is chair of Transport and Equity Analysis TEA Cost 17 Action TU1209 and a member of two TRB Committees: Travel Behaviour and Value, and Women 18 Issues in Transportation. Currently she is chair of Behavioural processes sub-committee of the 19 Transportation Research Board, and works for the Urban Innovation Action MaresMadrid.

\section{Yoram Shiftan}

21 Yoram Shiftan is a Professor of Civil and Environmental Engineering in the Technion, and the 22 head of Technion Transportation Research Institute (currently on Sabbatical at Northwestern 23 University, Chicago, IL). Prof. Shiftan teaches and conducts research in travel behavior with a 24 focus on activity-based modeling and response to policies and emergency situations, the complex 25 relationships between transport, the environment, land use, and health; transport economics and project evaluation. Prof. Shiftan was the editor of Transport Policy for the last six years, and the previous chair of the International Association of Travel Behavior Research (IATBR). Prof. Shiftan received his $\mathrm{Ph} . \mathrm{D}$. from MIT and since then has published dozens of papers and co-edited four books.

\section{$30 \quad$ Otto Anker Nielsen}

31 Otto Anker Nielsen is professor in Traffic Modelling and head of the Division of Transport 32 Modelling at DTU Management Engineering and head of the "Transport DTU" center. He has 33 participated in a number of EU-projects as Danish team-manager, international leader of 34 work-packages, and as member of scientific committees. His main reserach interests are traffic 35 models, route choice, impact analyses, public transport and GIS. He is a member of international 36 and Nordic research networks. visiting professor at University of Montreal and TUDelft. 